\title{
Mechanism and Therapy of Brain Edema after Intracerebral Hemorrhage
}

\author{
Haiping Zheng Chunli Chen Jie Zhang Zhiping Hu \\ Department of Neurology, The Second Xiangya Hospital of Central South University, Changsha, China
}

\section{Key Words}

Brain edema · Hematoma - Intracerebral hemorrhage . Inflammation

\begin{abstract}
Background: Intracerebral hemorrhage (ICH) is a subtype of stroke with a severe high mortality and disability rate and accounts for about $10-15 \%$ of all strokes. The oppression and destruction by hematoma to brain tissue cause the primary brain injury. The inflammation and coagulation response after ICH would accelerate the formation of brain edema around hematoma, resulting in a more severe and durable injury. Currently, treatments for $\mathrm{ICH}$ are focusing on the primary injury including reducing intracranial hypertension, blood pressure control, and rehabilitation. There is a short-of-effective medical treatment for secondary inflammation and reducing brain edema in $\mathrm{ICH}$ patients. So, it is very important to study on the relationship between brain edema and ICH. Summary: Many molecular and cellular mechanisms contribute to the formation and progress of brain edema after $\mathrm{ICH}$; inhibition of brain edema provides favorable outcome of ICH. Key Messages: This review mainly discusses the pathology and mechanism of brain edema, the effects of brain edema on $\mathrm{ICH}$, and the methods of treating brain edema after $\mathrm{ICH}$.

(c) 2016 S. Karger AG, Basel
\end{abstract}

\section{KARGER}

E-Mail karger@karger.com

www.karger.com/ced

\section{Introduction}

Intracerebral hemorrhage (ICH) accounts for about $10-15 \%$ of all strokes with high mortality [1], 1-month mortality of $\mathrm{ICH}$ is approximate $40 \%$ and it increases with age [2]. In the last 2 decades, the high mortality and morbidity of ICH does not decrease over time. In the first few hours after ICH onset, primary brain injury by ICH is mainly caused by the oppression and destruction to the near tissue by hematoma formation. And hematoma could also increase the intracranial pressure; it can even induce brain herniation. The inflammation, thrombin activation, and erythrocyte lysis caused by primary injury could promote the formation of brain edema, which is associated with poor outcome, and could cause more severe and durable injury [3]. Brain edema is a pathological phenomenon that water and brain tissue volume increase. Brain edema after ICH can be divided into perihematomal edema (PHE) and intrahematomal edema. Most patients could survive the initial injury of smaller hemorrhage, but the secondary injury may result in severe neurological deficits and even death [4]. The mechanism of brain edema is complicated; vasogenic factors, thrombin formation, erythrocyte lysis and hemoglobin $(\mathrm{Hb})$ toxicity [5] have been proved to be related to brain edema growth [6]. Currently, therapy for ICH focuses on the primary injury and preventing bleeding again, including de- 
hydration and hemostasis. But, all these treatments fail to provide a promising functional outcome or decrease mortality. In recent years, many studies focus on the mechanism of secondary inflammation that can cause brain edema and this may provide new therapy targets for ICH [7]. Animal experiments demonstrated that fingolimod could reduce edema, cell apoptosis and cerebra atrophy and show neuroprotective function in ICH rats [8]. A similar result was observed in a clinical study [9]. Likewise, dexamethasone can reduce cerebral cell apoptosis and inhibit inflammation [10], and deferoxamine (DFX) provides new therapy target [11]. But before these immunomodulators or other anti-inflammatory agents are used clinically, more experiments are needed.

\section{Mechanism of Edema}

Brain edema increases in the first $24 \mathrm{~h}$ progressively and increases rapidly 3 days after onset, reaches its initial peak at the 4th or the 5th day and remains elevated slowly until 9-14 days and then decreases [12]. PHE develops in response to clot retraction and hydrostatic pressure change [13], mass effect, thrombin formation, erythrocyte lysis, Hb toxicity, complement activation, plasma proteins leakage and blood-brain barrier (BBB) disruption [5]. All of inflammation, thrombin activation and red blood cell (RBC) lysis production contribute to $\mathrm{BBB}$ disruption resulting in edema formation, and it can be diversified into 3 phases: (1)clot retraction could force the serum into the perihematomal space to form vasogenic edema ( $1 \mathrm{~h}$ after ICH; fig. 1), (2) inflammation (fig. 2) and thrombin activation (fig. 3)-related cytotoxic brain edema through clotting cascade (peaking at 1-2 days), and (3) erythrocyte lysis and $\mathrm{Hb}$ toxicity-related injury (delayed edema formation at about day 3; fig. 4) [14]. Both elevated oncotic pressure of perihematoma space due to the infiltration of blood components from hematoma and BBB disruption caused by inflammation, thrombin cascade and erythrocyte lysis products can aggravate vasogenic edema. However, oxidative stress induced by vasogenic edema, and release of cytotoxic substance could induce cytotoxic edema. So, vasogenic edema and cytotoxic edema interact with each other and lead to a vicious circle. Intrahematomal edema is mainly caused by tension hematoma. Tension hematoma is related to the formation of capsule-like granulation tissue during the absorption of a hematoma. The capsule-like granulation can limit the absorption of liquified hematoma and cytotoxic substance. Subsequently, the oncotic pressure in-

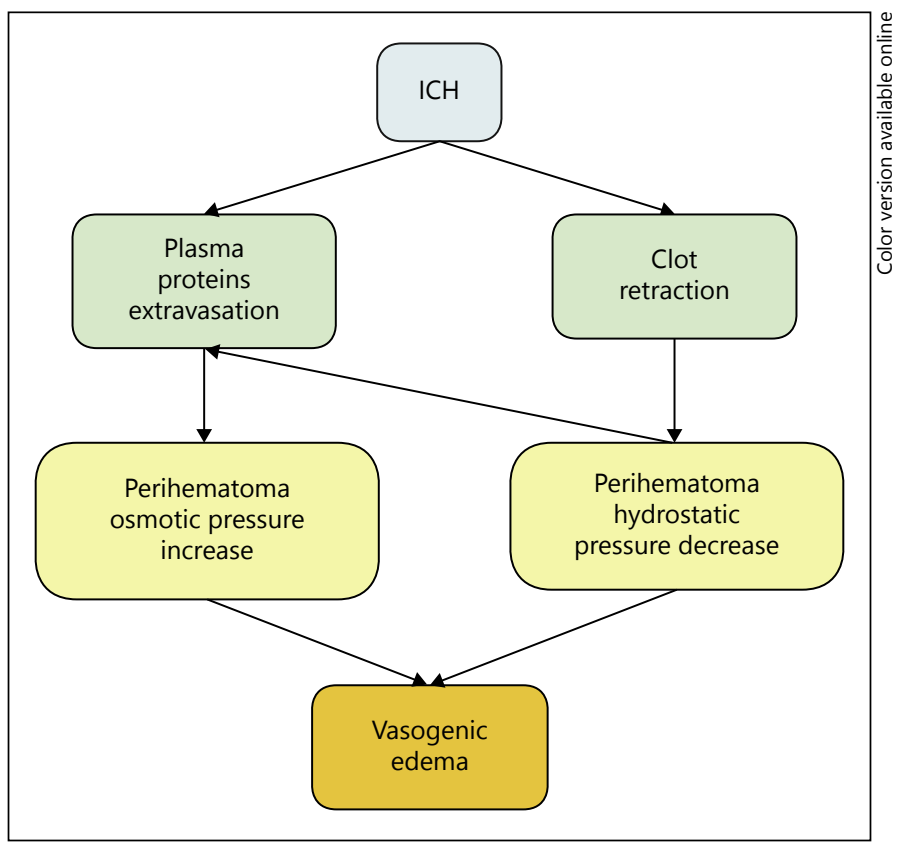

Fig. 1. Mechanism of vasogenic edema.

side the hematoma increases and the infiltration of perihematoma water and plasma increases the tension inside the capsule progressively. Additionally, blood may leak repeatedly from the abundant capillaries contained in the granulation tissue resulting in hematoma enlarging [15].

\section{Vasogenic Factors}

Numerous studies show that during the early stage of $\mathrm{ICH}$, vasogenic factors can cause edema. Vasogenic factors mainly include clot formation and contraction [16], decrease in hydrostatic pressure around hematoma space [17] and extravasation of plasma proteins [13]. MRI done $2 \mathrm{~h}$ after onset of ICH shows edema in the area surrounding the hematoma [18].

Through MRI perfusion, weighted imaging and diffusion-weighted imaging, some experts found that water diffusion in the perihematoma edema increases significantly and is related to brain water volume independently, and they think that most of the brain water comes from plasma [19]. Injecting autologous blood (control group) or heparinized autologous blood (heparinized group) into brain parenchyma of pigs showed that edema increases significantly $1 \mathrm{~h}$ after ICH and lasts longer in the control group, while ther heparinized group showed no obvious edema. Meanwhile, they also experimented on rats by injecting thrombin or heparinized thrombin into cerebral parenchyma; the results of these experiments 


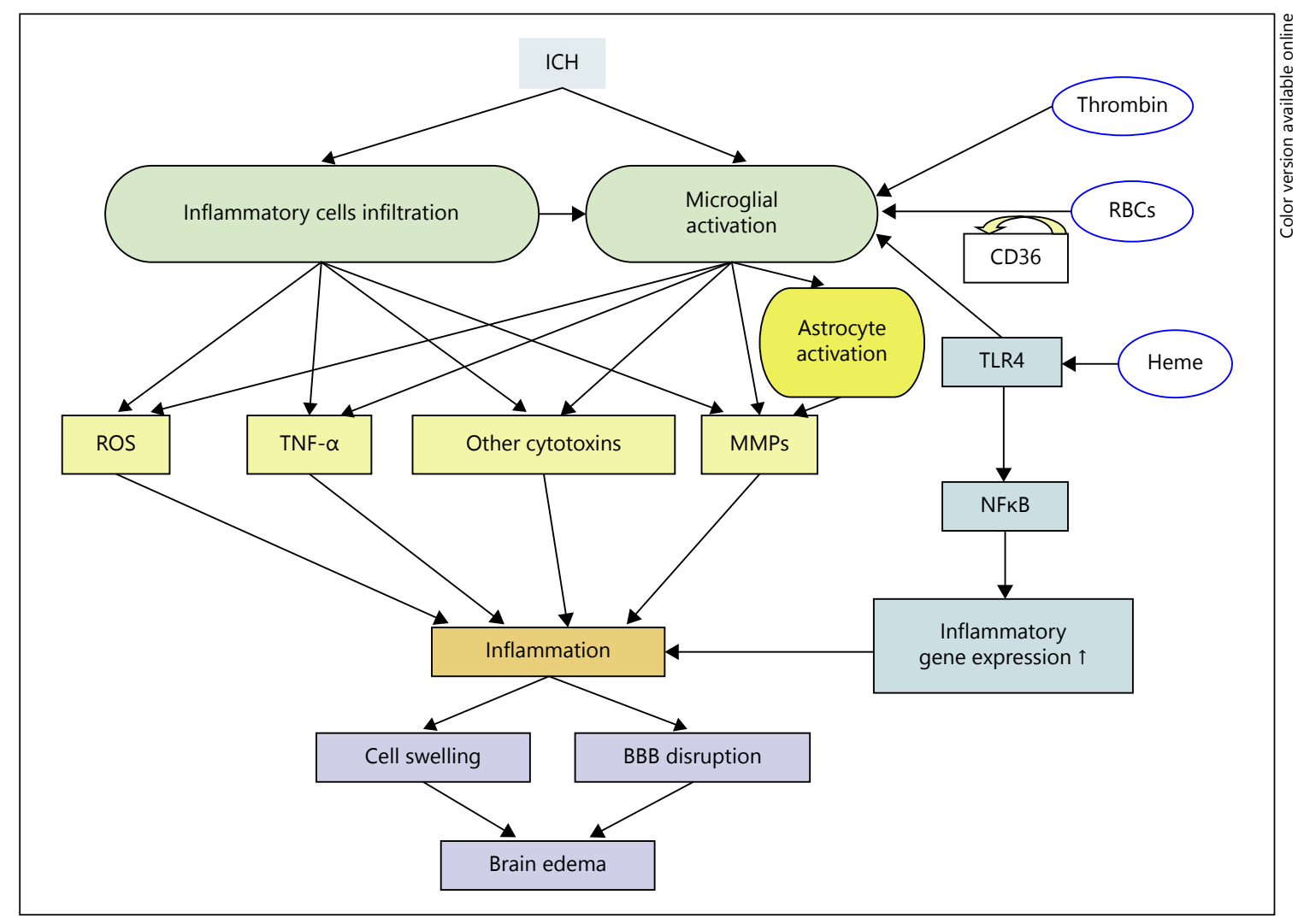

Fig. 2. Mechanism of inflammation induces edema.

demonstrated that the heparinized group showed significantly less edema. So, they concluded that the formation and existence of clot was important for the formation and progress of brain edema [16]. Compared with spontaneous ICHs (SICHs), thrombolysis-related ICHs have both lower absolute and relative edema observed in clinical test, indicating that intrahematomal blood clotting is a reasonable factor for the formation of hyperacute PHE [20]. Animal experiment showed that plasma proteins can be detected in the tissue around hematoma after $1 \mathrm{~h}$ of ICH when BBB is not destructed, and so the leakage of plasma proteins and related edema is not associated with $\mathrm{BBB}$ destruction in the hyperacute stage of ICH [13]. Clot contraction can decrease the perihematoma hydrostatic pressure; then it forces the plasma components into perihematomal space, which leads to an increase in perihematoma oncotic pressure close to the plasma level and water infiltration into the perihematomal space from blood followed [16, 21]. Furthermore, destruction by hematoma can induce a low metabolism of the perihematoma tissue, cell death and brain atrophy, which results in the enlargement of perihematomal space and decrease in hydrostatic pressure. Plasma can also induce oxidative stress and release of inflammatory mediators, which will promote the secondary brain injury besides vasogenic edema [22].

\section{Inflammation}

To clarify the cause of edema, Gong et al. [23] conducted an immunocytochemistry experiment on rats. It demonstrated that inflammatory response took place in and around the hematoma after ICH with the infiltration of neutrophils and macrophages and activation of microglia. Inflammation can cause cell swelling and BBB disruption, and then causes brain edema. Activated microglia and infiltrating leukocytes release cytotoxic mediators contributing to secondary injury. Clinical studies have proved that RBCs infiltrate into cerebral immediately, along with leukocyte from peripheral blood, macrophages and plasma proteins [24], and animal experiments had shown that CD4+ T lymphocytes were the main cause of brain leukocyte infiltration [25]. But within $12 \mathrm{~h}$ after onset of $\mathrm{ICH}$, inflammatory macrophages and dendritic cells comprise a majority of infiltrating leu- 


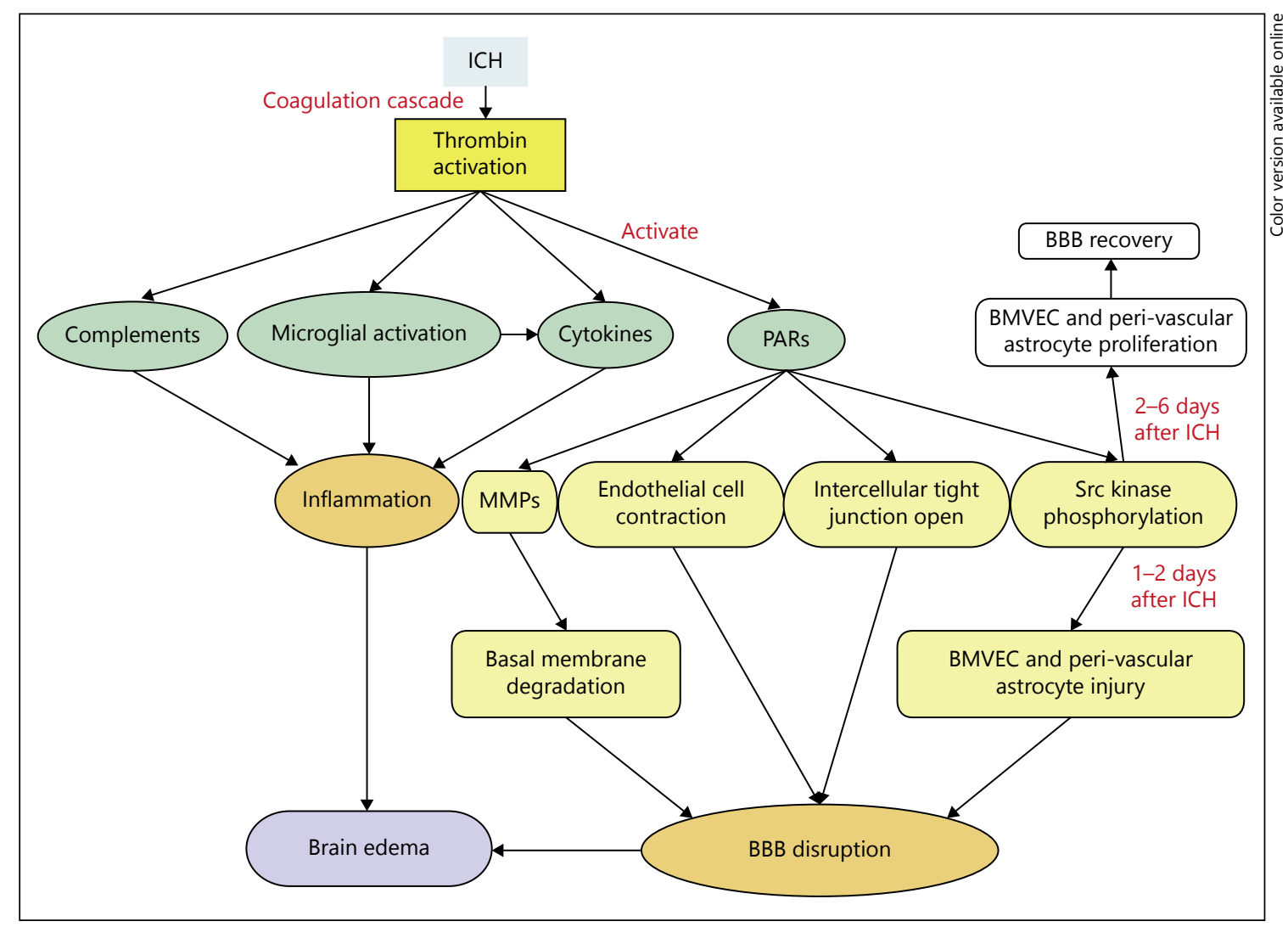

Fig. 3. Mechanism of thrombin induces edema.

kocytes [26]. Neutrophils or polymorphonuclear leukocytes (PMNs) are the first leukocytes to infiltrate the nervous system within $4-5 \mathrm{~h}$ after $\mathrm{ICH}$, and reach a peak value at 3 days [27]. PMNs may cause direct neurotoxicity to $\mathrm{ICH}$ brain by release matrix metalloproteinases (MMPs), reactive oxygen species (ROS), and tumor necrosis factor-alpha (TNF-alpha) or other cytokines. Animal experiments demonstrated that PMNs can induce inflammation, but resting neutrophils could reduce the permeability of BBB and activated neutrophils showed a neutral effect [28]. So, neutrophils-induced inflammation depends on MMPs, ROS and cytokines instead of reducing permeability of BBB. Leukocytes exist only for about 2 days after infiltrating into hemorrhagic brain, but it can cause further damages by stimulating microglia and macrophages [14]. Microglia activation can also be mediated by CD36 in erythrocyte [29], thrombin [30], and by heme via toll-like receptor 4 (TLR4) signaling pathways [31]. Activated microglia/macrophages appear in and around the injury tissue as early as $1 \mathrm{~h}$ after ICH [32]. The primary role for resident microglia cell activation is to clear the hematoma, but excessive microglial activation can express and release diverse toxic factors, which contribute to secondary injury, such as cytokines (interleukin (IL) $-1 \beta$ and others), chemokines, proteases, ROS, prostaglandins, cyclooxygenase-II and heme oxygenase (HO) $[30,33]$. TLRs are molecules that play a critical role in the induction of innate and adaptive immunity, and TLR4 is expressed in microglia and some neurons $6 \mathrm{~h}$ through 7 days after ICH [34]. Activated TLR4 can mediate microglial autophagy and activation [35], and induce the dissociation of kappa-B $(\kappa B)$ with nuclear factor- $\kappa \mathrm{B}$ (NF$\kappa \mathrm{B})$; then NF- $\kappa \mathrm{B}$ activates and regulates the transcription of genes related to inflammation after it translates into the nucleus. Animal experiments showed that neutrophil, monocyte, inflammatory monocyte and microglia increased significantly in the perihematomal brain compared to TLR4-deficient mice, and the leukocytes infiltrated from the peripheral blood [36]. Microglia reaches a peak at $72 \mathrm{~h}$, begin to decrease by a week and return to basal levels by 21 days after ICH. Astrocytes can also express MMPs together with activated microglia, and controlling microglia-astrocyte interactions may be a potential way to minimize ICH-induced injury [7]. So, the ear- 


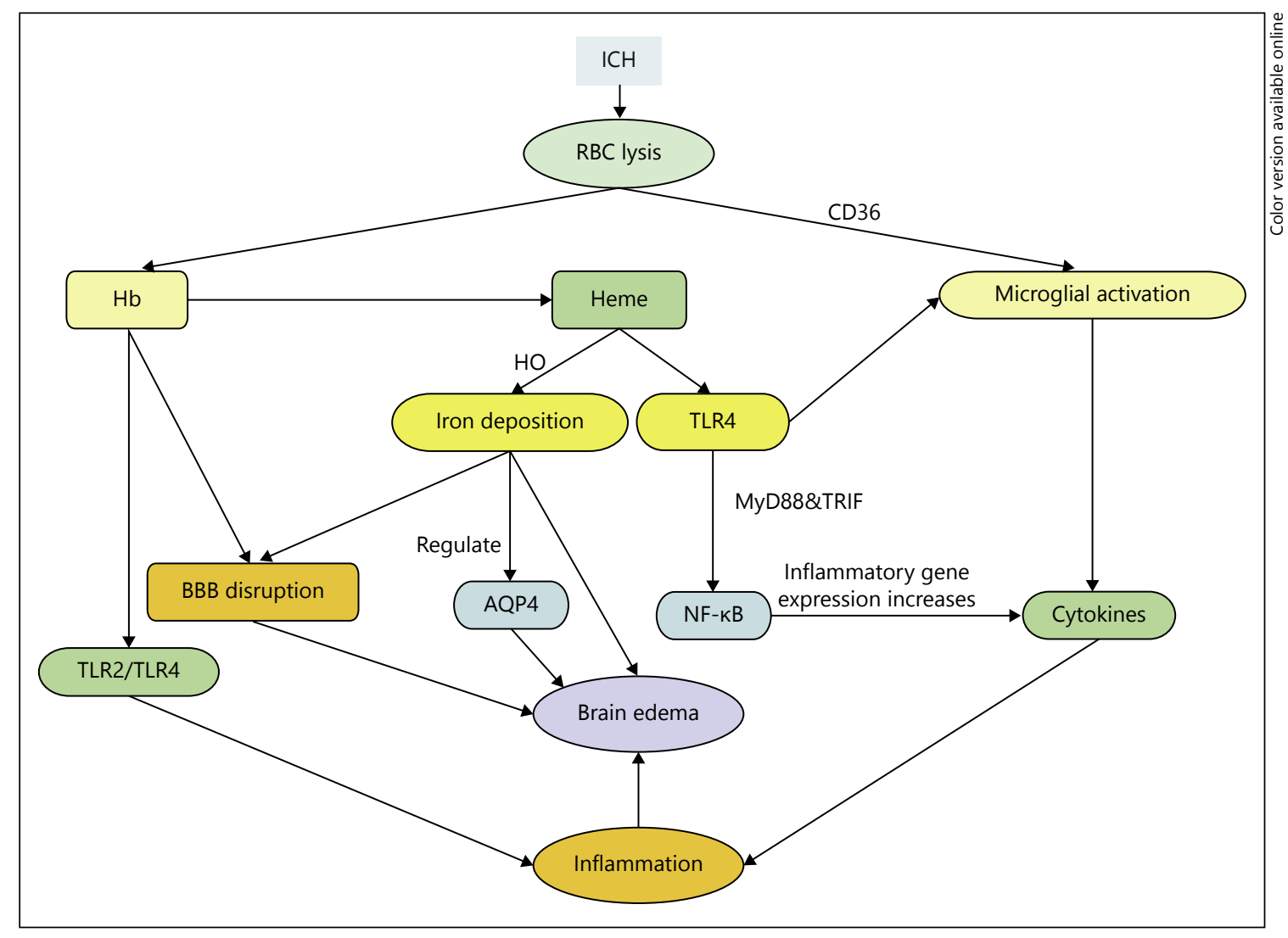

Fig. 4. Mechanism of RBC lysis production induces edema.

ly stage of the inflammatory response and brain edema after ICH is caused by microglia activation, infiltration of inflammatory cells including leukocytes and macrophages, and accumulation of proinflammatory mediators released from these cells.

\section{Thrombin}

The coagulation cascade is activated as soon as blood flows into the brain tissue, and thrombin is an essential component of the coagulation cascade $[4,5]$. Thrombin induces disruption of BBB function and parenchymal cell death, and both of BBB disruption and cell toxicity by thrombin can trigger the formation of brain edema after ICH [37]. Thrombin induces endothelial cell contraction and the opening of intercellular tight junctions by activating protease-activated receptors (PARs), which are thrombin receptors [38]. MMPs protein is a zinc-containing extracellular-matrix degrading protease and they can degrade the entire extracellular matrix after being activated. MMP-9 can be an important biomarker of complications and for selecting patients for trials investigating hemicraniectomy in $\mathrm{ICH}$ [39]. MMP-2 protein can degrade substrates including collagens IV, V, VII, and X, gelatin, laminin, and fibronectin, most of which are components of capillary basal membranes. So MMP-2 activation leads to basal membrane degradation that is a vital part of BBB. And thrombin can trigger MMP-2 expression and membrane degradation by activating PARs [38]. Thrombin also activates the phosphorylation of Src kinase (a proto-oncogene protein family with tyrosine protein kinase activity), which leads to the injury of brain microvascular endothelial cell (BMVEC) and peri-vascular astrocyte, resulting in the disruption of $\mathrm{BBB}$ and formation of edema through its PARs [40, 41]. However, Src kinase proto-oncogene members can stimulate the proliferation of newborn BMVECs and peri-vascular astrocytes after 2-6 days; it then promotes the resolution of edema and the recovery of BBB permeability. Thrombin also releases nitric oxide, TNF- $\alpha$, IL-12, and IL- 6 , and thrombin-induced brain injury is partly mediated by complement [42]. Activation of microglia and mitogenactivated protein (MAP) kinases also play an important role in causing thrombin-induced neurological injury after ICH [43]. 


\section{RBC Lysis Production}

RBCs lysis occurs within $24 \mathrm{~h}$ of ICH and induces the release of $\mathrm{Hb}$ and heme, which are taken up by microglia and neurons [14]; heme can be degraded by $\mathrm{HO}$ into biliverdin, carbon monoxide and iron. All of $\mathrm{Hb}$, heme and iron causes significant brain edema after the first $24 \mathrm{~h}$, which is related to a threefold increase of $\mathrm{BBB}$ permeability [44]. Animal experiments showed that intracerebral injection of packed RBCs does not produce significant edema on the first day but does at 3 days; so RBCs can cause delayed brain edema, which results from cellular lysis and $\mathrm{BBB}$ disruption by $\mathrm{RBCs}[44,45]$. Brain iron is an erythrocyte degradation product; iron deposition is found in the perihematomal brain tissue during the 1st day after $\mathrm{ICH}$, peaking after 7 days and remaining at a high level for at least 2 weeks, and perihematoma water content increases progressively over course of time [46]. Aquaporin-4 (AQP4) is involved in brain volume homeostasis and water balance; AQP4 is localized in perihematomal region at $6 \mathrm{~h}$ post-ICH and AQP4 mRNA and AQP4 protein are increased post-ICH [47]. So, edema post-ICH is closely connected with AQP4. Upregulation of AQP4 around hematoma brain is observed and reached a peak at 3-7 days, and animal experiments showed that the changes of brain water content are accompanied by an alteration of AQP4, and this expression is affected by iron concentration [46]. Clinical study demonstrates that iron overload is associated with the progress of PHE indicating a poor outcome and high in-hospital mortality [6]. And heme can promote microglial activation through TLR4; this in turn will induce NF- $\mathrm{kB}$ activation through the myeloid differentiation primary response gene 88 (MyD88) or toll/IR-1 domain-containing adaptor protein-inducing interferon-beta (TRIF) signaling pathway, and finally increase cytokine expression and inflammatory injury in $\mathrm{ICH}$ [31]. Hb can trigger inflammation after ICH through the assembly of TLR2/TLR4 heterodimers, and MyD88 is required for ICH-induced TLR2/TLR4 heterodimerization [48].

In addition to all the discussion mentioned earlier, arginine vasopressin (AVP) receptors, glutamate and endothelin-1 (ET-1) may also be involved in the formation of brain edema. Experiments showed that AVP can induce the formation of brain edema by effects on astrocytes after ischemic stroke and the induction can be decreased by AVP receptors antagonist $[49,50]$. And, animal tests have found that AVP receptors antagonist SR49059 significantly decreases cerebral edema at 24 and $72 \mathrm{~h}$ post-ICH injury and improved neurobehavioral deficits at $72 \mathrm{~h}$ [51]. So, AVP receptors may play an important role in the formation of edema after ICH through reduced BBB permeability or AQP4 levels, but the details of the mechanism are still unknown [52]. An in vivo microdialysis study shows that glutamate, taurine and asparagines accumulate transiently in extracellular fluids in the perihematoma region during the early period of $\mathrm{ICH}$. These amino acids may play an important role in the pathology of ICH, but the intricacies of the mechanism are not very clear [53]. A recent study shows that blood glutamate grabbing cannot reduce the hematoma nor improve the neurologic deficit in ICH but is a safe excitotoxic treatment modality [54]. Animal experiments demonstrated that ET-1 expression increased significantly at $6,12,18$, and $24 \mathrm{~h}$ after $\mathrm{ICH}$, and they observed a positive correlation between the number of ET-1-positive endothelial cells and BBB permeability [55]. New findings show that ET-1 can lead to an increase in gene expression, including genes associated with the inflammatory response, oxidative stress, heme metabolism and iron homeostasis [56]. So, ET-1 may be related with BBB disruption and it plays an important role in causing the secondary injury after $\mathrm{ICH}$.

\section{Effects of Edema}

Studies have shown that brain edema is significantly associated with hematoma enlargement and increased midline shift, which lead to poorer functional outcome of ICH [4]. Mass effect can contribute to the formation of PHE [5]; it can also be a result of PHE [57]. Clinical observation shows that mass effect progresses within 2 days after ICH due to hematoma enlargement, and progresses again during the second and third weeks because of increased brain edema [57]. So, we can see that the interaction between mass effect and edema may lead to an unfavorable outcome. PHE may be a risk factor of acute progressing hemorrhagic stroke, and delayed PHE may contribute to subacute progression of hemorrhagic stroke, both these 2 types of stroke have worse clinical outcome than the nonprogressing types of hemorrhagic stroke [15]. Multivariable logistic regression analysis shows that absolute edema volume is not related to function outcome nor mortality, but relative edema volume (absolute edema volume/hematoma volume) during the first $24 \mathrm{~h}$ after ICH is an independent predictor of favorable 12-week functional outcome in hyperacute $\mathrm{SICH}$ without intraventricular extension [58]. Similarly, in a prospective cohort study, the relative edema is proved to be associated with an improved outcome at 12 weeks but 


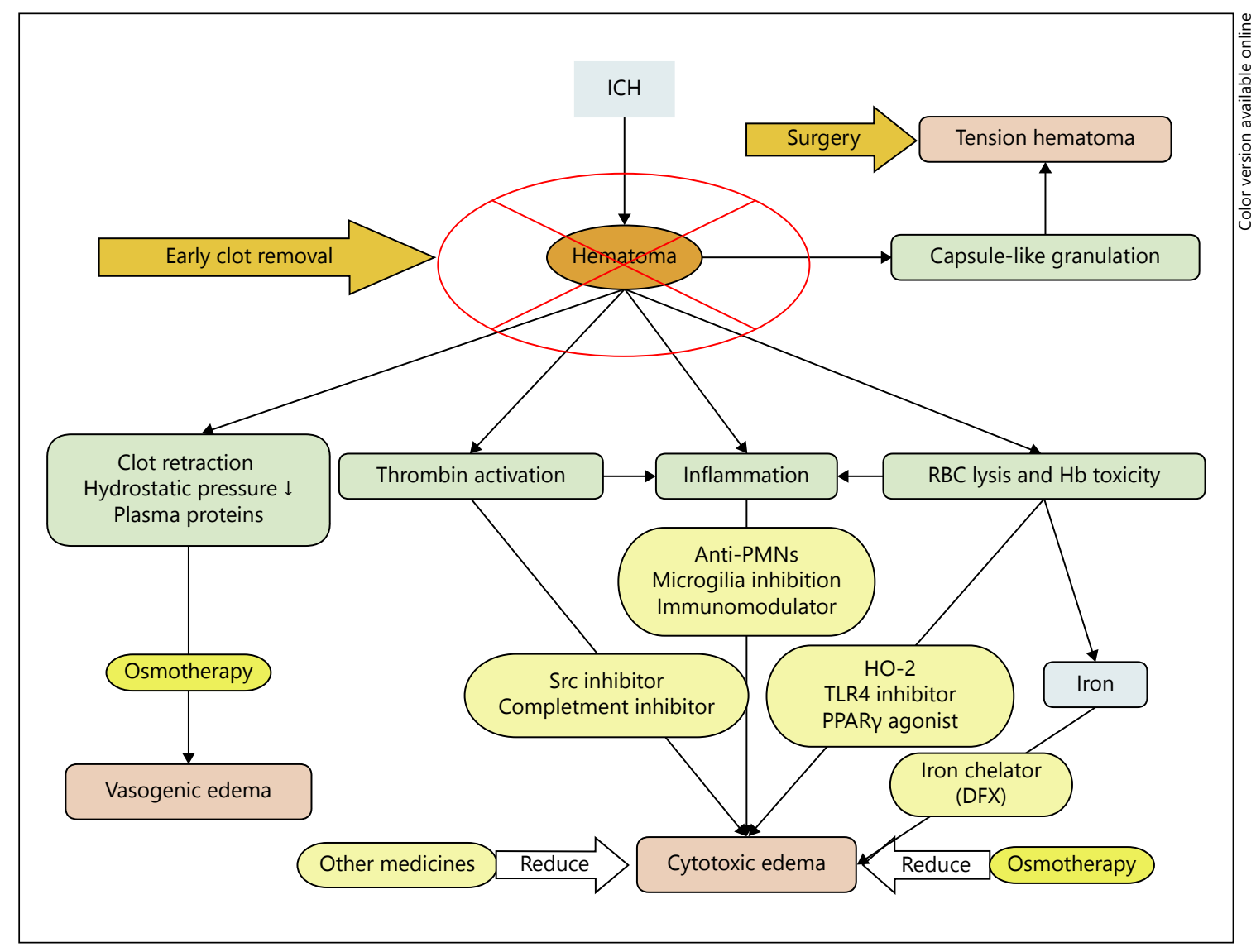

Fig. 5. Treatments of brain edema after ICH.

is not related to mortality in supratentorial SICH without intraventricular extension [59]. And results demonstrate that hematoma volume is the strongest independent predictor of a poorer prognosis of supratentorial SICH. It seems that absolute edema volume is not related to the outcome significantly, but it can contribute to hematoma expansion, which in turn independently predicts mortality. They excluded infratentorial SICH and those with intraventricular extension, as these $2 \mathrm{fac}-$ tors have been found to be associated with poor prognosis $[58,59]$.

\section{Treatments of Brain Edema after ICH}

Currently, treatments for ICH mainly focus on the primary injury and on preventing bleeding again; focus is also directed toward primary supportive treatment, including dehydration, hemostasis, blood pressure and intracranial pressure monitoring, and so on. All these therapies fail to provide a promising favorable outcome or decrease mortality of ICH. Recently, some experiments reviewed secondary inflammation, which contributes to brain edema and the results of these experiments may provide new ways of treatment for ICH [7]. Medical treatments of treatment on brain edema post-ICH include inhibition of inflammation, thrombin activation and $\mathrm{Hb}$ degradation products-mediated toxicity [60], traditional dehydration and so on (fig. 5). A clinical study shows that blood pressure reduction (systolic blood reduction goals are 170-199, 140-169 and 110-139 mm Hg, respectively) can reduce hematoma expansion and brain edema ratio after ICH with no significance between every group [61]. However, some large clinical studies show that intensive and continuous blood pressure reduction in the acute phase of ICH can improve functional outcomes by decreasing the hematoma expansion rate, and blood pressure should be controlled to be under $140 / 90 \mathrm{~mm} \mathrm{Hg}$ in the first hour after onset or within $24 \mathrm{~h}$ [62-64]. And these new therapeutic strategies focusing on multiple inflammatory pathways seem to be more effective than those focusing on single pathways [65]. Besides these new 
therapies, another effective way is surgical treatment to remove hematoma, which will reduce mass effect and hematoma-induced injury [60].

\section{Traditional Dehydration Therapy}

Dehydration is often used to decrease intracranial pressure during the acute phase of $\mathrm{ICH}$, and hypertonic dehydration of somotherapy is the most common treatment. Usual osmotherapy medicines are mannitol, glycerin fructose and albumin, other dehydrants include furosemide, glucocorticoid, acetazolamide and so on, and mannitol is the most widely used dehydrant. We should choose and use dehydrants on the basis of the brain edema type and evaluation of BBB integrity, as brain edema mechanism differs from each other.

Animal experiments found that after an injection of mannitol through the internal carotid artery, BBB disruption was observed and BBB permeability increased by $4-5$ times at $5 \mathrm{~min}$ and then reversed within minutes, the mechanism may be that mannitol can induce the shrinkage of cerebrovascular endothelial cells and vasodilatation $[66,67]$. Hence, the use of mannitol may lead to the opening of BBB and aggravate brain edema before BBB is disrupted (within $6 \mathrm{~h}$ after ICH generally). Pharmacokinetics study on mannitol for treatment of vasogenic edema shows that about $84 \%$ of the infused mannitol is excreted through urine. But mannitol accumulation is detected in the cerebral tissue after multiple injections, even exceeding the mannitol concentration in the plasma; this experiment observed a reversal of the osmotic concentration gradient between plasma and edematous brain, which can aggravate vasogenic brain edema. This study demonstrates that a single dose of mannitol is unable to reduce brain water content in edematous brain tissue or edema progression after $4 \mathrm{~h}$ of injection, but multiple doses can increase brain water content in edematous tissue [68]. Mannitol accumulates in the injured brain tissue, which would increase osmotic pressure; then water in perihematoma flows into the hematoma; this results in hematoma expansion even midline shift. Mannitol should be used while being closely monitored for plasma osmotic pressure; mannitol is not suitable to use when plasma osmotic pressure is $>320 \mathrm{mOsm}$ because high plasma osmotic pressure leads to dehydration, but mannitol can increase osmotic pressure of hematoma and reverse the osmotic pressure gradient [69]. Meantime, the early use of mannitol can shrink the normal brain and increase the pressure gradient between hematoma and normal brain. So, for those ICH patients who are still bleeding, early use of mannitol may lead to ICH progress [69]. A random- ized controlled study on 128 supratentorial ICH patients shows that mannitol $(20 \%, 100 \mathrm{ml}$ every $4 \mathrm{~h}$ for 5 days, tapered in the next 2 days) failed to improve the outcome at the end of 1 month and decrease mortality significantly [70]. Systematic reviews show similar results that there is not enough evidence to support the routine use of mannitol in acute ICH patients without increased intracranial pressure, but intracranial pressure should be monitored closely [71]. When there exist clinical features or image examination changes of intracranial hypertension, especially brain herniation, mannitol should be used immediately to decrease intracranial pressure. Hypertonic saline ( 3 or $23.4 \%$ ) can also be used as a dehydrant, which has a more lasting effect than mannitol without BBB disruption [72]. But hypertonic saline use has limitations, as it can cause disorders in water and salt metabolism. Animal experiments have demonstrated that mannitol produces a dose-dependent increase in plasma osmolality and reduction of brain water content, and furosemide alone shows no effect on plasma osmotic pressure nor brain water content [73]. Combination of mannitol and furosemide has a greater effect on plasma osmolality and reduction of water content than mannitol alone in the rat ICH model [73]. Combination of furosemide and hypertonic saline has a better effect on reducing brain water content compared with hypertonic saline alone, and the combination causes no more increase of osmolality and sodium concentration than that induced by hypertonic saline alone [74]. For subacute progressing, ICH excluding rebleeding after $\mathrm{CT}$, dehydrant and intracranial pressure monitoring should be applied [75].

In conclusion, dehydration is not recommended for ICH patients without intracranial hypertension. When $\mathrm{BBB}$ is not disrupted (within $6 \mathrm{~h}$ after ICH generally) or plasma osmotic pressure is $>320 \mathrm{mOsm}$, mannitol especially frequent mannitol using is not suitable, hypertonic saline alone or with furosemide can be alternative options. However, if there is intracranial hypertension especially brain herniation or progressing ICH excluding rebleeding, dehydration should be used. In case the anticipated dehydration target after multiple use of mannitol is not achieved, combination with furosemide or hypertonic saline can be a substitute for adding mannitol dose, as multiple doses of mannitol can increase brain water content in edematous tissue.

\section{Inhibition of Inflammation}

Inflammation plays an important role in brain edema after ICH and it can induce cytotoxic edema through multiple ways. So, inhibition of inflammation may be 
beneficial to ICH. In the early stages of $\mathrm{ICH}$, inflammation is mainly caused by PMNs infiltration and microglia activation.

Inhibition of PMNs Infiltration and Microglia

Activation

Neutrophil depletion by using anti-PMN can reduce BBB permeation, MMP-9 expression, perihematomal axonal injury and the astrocytic and microglia/macrophage responses and provide a better outcome of ICH [76, 77]. Similarly, MMP inhibitor (GM6001), ROS scavengers or TNF-alphaR neutralizing antibody can decrease the neurotoxicity caused by PMNs, and then protect neurons from injury [27].

Activation of microglia can lead to the release of diverse toxic factors (such as cytokines, proteases, ROS and so on), which contribute to secondary injury after ICH. So, inhibition of microglia activation may be beneficial to $\mathrm{ICH}$. It has been proved that Minocycline, an inhibitor of microglia activation, can reduce $\mathrm{PHE}, \mathrm{ICH}$-induced brain tissue loss and improve functional outcome in ICH rats [78]. And minocycline can also ameliorate the damage after ICH by protecting BBB, decreasing TNF-alpha and MMPs expression, and reducing microvessel loss and extravasation of plasma proteins and the numbers of TNFalpha-positive cells and neutrophils [79]. In another rat experiment, it was found that coinjection of iron and minocycline significantly reduced brain edema, BBB leakage and brain cell death caused by iron, compared with an injection of iron alone [80]. Tuftsin, another inhibitor of microglia activation, can reduce brain edema after ICH as well [81]. Tuftsin fragment $1-3$, a macrophage/microglial inhibitory factor, is a neuroprotective agent for $\mathrm{ICH}$ treatment, as it can reduce stroke volume, edema, degenerating neurons, and neurobehavioral deficits [81]. TLR4 can mediate the autophagy of microglia; treatment of autophagy inhibitor (3-methyladenine) decreases microglial activation and inflammatory injury [35].

\section{Immunomodulator}

Edema is significantly associated with hematoma enlargement and increased midline shift, resulting in poorer functional outcome of $\mathrm{ICH}$. Agents that can reduce PHE process provide protective effects for $\mathrm{ICH}$. Fingolimod (FTY720), a sphingosine 1-phosphate receptors analog, is an immune-modulating drug that can prevent the migration of lymphocytes from primary and secondary lymphoid organs and may ameliorate cerebral inflammation, it can improve neurobehavior and cognitive outcomes in experiment ICH mice [82]. Fin-

Mechanism and Therapy of Brain Edema after ICH golimod can also reduce brain edema, apoptosis and brain atrophy [8]. Further study shows that fingolimod decreases not only the number of perihematomal Tlymphocytes in brain but also the expressions of cytokines (interferon- $\gamma$, and IL-17) [83]. And in this animal experiment, fingolimod had functions of reducing brain edema, improving short-term sensorimotor function and long-term motor and coordination and cognitive function in rats after experimental ICH [83]. Fu et al. [9] conducted a 2 -arm proof-of-concept study including 23 patients with primary supratentorial ICH with hematomal volume of 5-30 $\mathrm{ml}$. These 23 patients received standard treatment alone (control group) or combined with fingolimod ( $0.5 \mathrm{mg}$, orally for 3 consecutive days). Results revealed that the fingolimod group has a significantly better outcome compared with that of the control group. Patients treated with fingolimod have a higher Glasgow Coma Scale score, lower National Institutes of Health Stroke Scale score, improved neurologic function and fewer ICH-related lung infections without differences in the occurrence of adverse events when compared with the control group. Dexamethasone can promote the recovery of ICH injury by inhibiting the inflammatory response and reduce brain edema because of its capacity to decrease apoptotic cell death and inhibiting the intercellular adhesion molecule-1 and MMP-9 expression $[10,84]$.

\section{Inhibition of Thrombin}

Thrombin inhibitor, Hirudin, can prevent the BBB disruption caused by thrombin, but it can also affect the clotting hemostatic function; it may not be an assured form of treatment [40]. Acute administration of the Src inhibitor PP2 blocks the thrombin pathway, decreases glucose hypermetabolism and cell death around $\mathrm{ICH}$, and reduces brain edema that occurs after ICH without affecting coagulation $[40,41]$. But delayed and chronic administration of $\mathrm{PP} 2$ prevents edema resolution and $\mathrm{BBB}$ repair because chronic Src kinase activation can promote the BBB repair after ICH. N-acetylheparin is an inhibitor of complement activation; it can attenuate the brain injury induced by thrombin, and it may be a neuroprotective agent for ICH [85]. Both argatroban or cycloheximide can prevent thrombin cytotoxicity and exhibit an obviously neuroprotective function against ICH-induced injury; MAP kinase inhibitor (PD98059) and a c-Jun Nterminal kinase inhibitor (SP600125) can also prevent ICH-induced neuron loss [43]. However, these drugs have no effect on hematoma volume or brain edema after $\mathrm{ICH}$. 
Inhibition of RBCs Lysis and Hb Toxicity

$\mathrm{RBC}$ lysis releases $\mathrm{Hb}$ and heme; brain iron is a heme degradation product; excess iron released is found to induct secondary brain injury [46]. DFX, an iron chelator, has been proved to be neuroprotective in nature in many $\mathrm{ICH}$ animal experiments. By injection of autologous blood into the pigs cerebral, Gu et al. [86] found that DFX can reduce perihematoma volume, through chelating iron directly and may be also by inhibiting oxidative stress-induced cell death. In another experiment, results showed that DFX can reduce white matter edema after ICH in piglets, decrease levels of TNF-alpha and receptor-interacting protein kinase 1 [87]. A rats experiment showed that DFX can penetrate BBB rapidly and reduce $\mathrm{ICH}$-induced ventricle enlargement, brain edema and brain atrophy without severe side effects [88]. DFX can reduce free iron in cerebrospinal fluid as well as ICH-induced neurological deficits and acute neuronal death in rat experiment. It can also inhibit the endogenous response to ICH and the upregulation of ferritin and AQP4, which are related to a poor outcome of ICH $[46,89,90]$. Pro-oxidant heme, which is released from $\mathrm{Hb}$ catabolism of heme, plays an important role in the resolution of hematoma. HO controls the degradation of pro-oxidant heme and HO-2 may provide protection for ICH-induced brain injury [91]. Heme activates microglial via TRL4 signaling pathway, and TLR2 and TLR4 play an important role in the secondary injury $[31,48]$. So, inhibition of TLR2 and TLR4 may be beneficial for ICH and some experiments have proved this hypothesis. An ICH mouse model demonstrates that TAK-242 (ethyl (6R)6-(N-(2-chloro-4-fluorophenyl)sulfamoyl)cyclohex1-ene-1-carboxylate, Takeda), which is a TLR4 antagonist, can reduce brain water content, neurological deficit scores, and levels of inflammatory factors. TAK-242 also decreases the levels of deoxyribonucleic acid (DNA) damage, neuronal degeneration and the expression of TLR4 downstream signaling molecules [92]. Specific TLR4 antibody (Mts510) and TLR4-knockout have a similar function of reducing brain edema and neurological deficits [31].

An increasing number of proinflammatory mediators and cytotoxins are released by blood components after ICH. Lysis of extravasated erythrocytes in the hematoma releases cytotoxic $\mathrm{Hb}$, heme and iron, resulting in secondary injury. Phagocytic cells, brain's microglia and hematogenous macrophages can phagocytose and process extravasated erythrocytes and subsequent toxicity occurs before lysis after ICH. CD36 and catalase are proteins that can mediate phagocytosis of damaged, apoptotic, or se- nescent cells, including RBCs. Rosiglitazone is a peroxisome proliferator-activated receptor $\gamma$ (PPAR $\gamma$ ) agonist. It can increase PPAR $\gamma$-regulated gene (catalase and CD36) expression, but reduce proinflammatory gene (TNF- $\alpha$, IL$1 \beta$, MMP-9, and so on) expression and neuronal damage [29]. So, PPAR $\gamma$ agonist can promote the resolution of hematoma and is a potential treatment of $\mathrm{ICH}$.

\section{Other Medicines}

In addition to all that has been discussed earlier, there exist many other potential therapy targets for $\mathrm{ICH}$. The 3-hydroxy-3-methylglutaryl-coenzyme A reductase inhibitors or statins have pleiotropic effects, and continued statins use after $\mathrm{ICH}$ is associated to lower mortality within 6 months and early neurological improvement because of its anti-inflammation and neuroprotective function [93]. Depletion of GR-1-positive (GR-1(+)) cells by the administration of anti-GR-1 can reduce circulating GR$1(+)$ cells and astrocyte immunoreactivity and decrease brain neutrophils after $\mathrm{ICH}$; it may be a neuroprotective agent [94]. Nuclear factor erythroid 2-related factor 2 (Nrf2) is a key transcriptional factor for antioxidant response element-regulated genes and it can induce and upregulate cytoprotective and antioxidant genes that attenuate tissue injury. Nrf2 is neuroprotective by reducing leukocyte infiltration, excessive free radical oxidative injury, DNA damage, and cytochrome c release during the early phase of ICH [95]. Pyrroloquinoline quinone (PQQ) has roles of antioxidant properties, cofactor of dehydrogenase, and amine oxidase is a neuroprotective agent in experimental stroke and spinal cord injury models. Animal test demonstrates that PQQ can improve the locomotor functions, reduce the hematoma volumes and alleviate the expansion of brain edema after ICH. Also, pretreated rats with PQQ significantly reduce the production of ROS after ICH, probably due to its antioxidant effects [96]. SR49059, an AVP V(1a) receptor competitive antagonist is proved to have a function of reducing brain edema and neurobehavioral deficits after ICH by decreasing the BBB disruption and AQP4 levels [51, 52]. Animal experiments demonstrated that granulocyte-colony stimulating factor can protect ICH by reducing BBB permeation, cell apoptosis and brain edema [97]. Erythropoietin can protect $\mathrm{BBB}$ and decrease $\mathrm{BBB}$ disruption and brain edema post-ICH [98].

\section{Surgical Treatment}

Due to lack of optimal treatment of $\mathrm{ICH}$, clinicians have devoted to the hematoma clearance especially for patients with hematoma volume that is $>30 \mathrm{ml}$ or more, 
by surgical intervention or thrombolytic evacuation. The operation forms include craniotomy, decompressive craniectomy, stereotactic or transcatheter aspiration, laparoscopic aspiration and so on.

\section{Early Clot Removal}

A clinical study demonstrated that hematoma removal by surgery can significantly reduce the volume of the mass including brain edema and hematoma in putaminal hemorrhage patients as compared to the conservative group [99]. Another set of clinical data showed that surgical treatment of hypertensive putaminal hematoma with $30 \mathrm{ml}$ or more decreases mortality and provides better outcome compared with the non-operation group [100]. Burr hole craniectomy of hypertensive basal ganglia hemorrhage can decrease brain edema grades and reduce secondary injury by coagulation end productsactivated inflammatory cascade [101]. And the experiment showed that gross-total removal of hematoma group has a better outcome than the sub-total removal of the hematoma group; this indicates that residue hematoma can still promote secondary injury and may result in a comparatively worse result [101]. However, a parallel-group trial about surgical trial in ICH (STICH) found that early surgery (within $24 \mathrm{~h}$ after onset) has no overall benefit compared with initial conservative treatment for spontaneous supratentorial ICH patients [102]. Metaanalysis showed that early surgery before the patients deteriorate would improve $\mathrm{ICH}$ outcome for spontaneous supratentorial $\mathrm{ICH}$ patients without intraventricular hemorrhage meeting the conditions: undertaken within $8 \mathrm{~h}$ of ictus, the volume of the hematoma was $20-50 \mathrm{ml}$, the Glasgow Coma Score was between 9 and 12, or the patient was aged between 50 and 69 [103]. And large clinical randomised trial (STICH II) also showed that early surgery (within $12 \mathrm{~h}$ after onset) for spontaneous superficial ICH patients without intraventricular hemorrhage would improve clinical functional outcome, and no increasing death or disability rate was observed at 6 months [104]. Another meta-analysis about minimal invasive surgery (MIS) demonstrated that MIS can reduce primary and secondary brain injury for supratentorial $\mathrm{ICH}$ patients meeting the following conditions: age of 30-80 with superficial hematoma, Glasgow Coma Scale score of $\geq 9$, hematoma volume between 25 and $40 \mathrm{ml}$, and within $72 \mathrm{~h}$ after onset of symptoms [105]. For cerebellar hemorrhage, urgent clot removal should be undertaken before deterioration if there exists totally the 4th ventricular obliterated [106]. When cerebellar hemorrhage occurs with blood collections exceeding $3 \mathrm{~cm}$ in diameter

Mechanism and Therapy of Brain Edema after ICH or brainstem compression resulting in aggravating consciousness disturbance (Glasgow Coma Scale score $\leq 13$ ), clot clearance should be applied before the condition of the patient deteriorates to relieve oppression and save life. If cerebellar hematoma exceeds $3 \mathrm{~cm}$ in diameter but the 4 th ventricle is not totally obliterated, surgical clot removal may not be required and conservative treatment or ventricular drainage can be a feasible treatment [106108].

In recent years, some trials have shown that MIS or minimal-invasive hematoma evacuation in combination with thrombolytics have encouraging outcome [109, 110]. Animal experiments found that MIS can reduce the glutamate content [111], neurological deficit scores, perihematomal ET-1 levels, BBB permeability and brain water content compared to the model control group, especially performing MIS at 6-12 h after ICH [112]. In a cohort study, MIS combined with recombinant tissue-type plasminogen activator significantly reduced the 30-day mortality and without effects on early or delayed PHE formation [113]. MIS with local fibrinolysis decreased lethality from 35 to $21 \%$ among patients with parenchymal ICH and from 98 to $48 \%$ among patients with ventricular hemotamponade compared to treatment without use of fibrinolytics, and the local use of fibrinolytics had no systematic effect on the blood coagulation system [114]. Meta-analysis demonstrates that neuroendoscopic approach with external ventricular drainage may be a better management for intraventricular hemorrhage secondary to spontaneous supratentorial hemorrhage than neuroendoscopic with intraventricular fibrinolysis [115].

Early clot removal seems to have great benefit for ICH patients, but the effect of surgery is still controversial and depends on many factors, such as body condition, hematoma location, volume and so on. Clinicians should assess patients' condition comprehensively before surgical treatments.

Surgical Treatment for Intrahematomal Edema

Intrahematoma edema is mainly caused by tension hematoma. Tension hematoma is related to the formation of capsule-like granulation, and conservative treatment has no favorable effect. So, surgical treatment should be applied if tension hematoma is diagnosed after imaging examination. A clinical test from China found that for patients with tension hematoma, dehydration therapy fails to ameliorate symptoms, and surgery can improve clinical conditions and decrease intracranial pressure. And intracranial hematoma puncture drainage may be superior to craniotomy [116]. 


\section{Conclusions}

ICH is a subtype of stroke with severe outcome and is short of efficient treatment. The secondary injury induced by ICH is involved with numerous cellular and molecular mechanisms. Edema after ICH plays an important role in $\mathrm{ICH}$-induced injury and is associated with poor outcome of ICH. Vasogenic factors, inflammation, thrombin activation, $\mathrm{RBC}$ lysis and $\mathrm{Hb}$ toxicity contribute to the formation of brain edema after ICH. Dehydration therapy and new targets that block the inflammation cascade inhibit the thrombin activation, prevent or alleviate the lysis of $\mathrm{RBC}$, and surgical treatment may be effective treatments.
Immunomodulator such as fingolimod or dexamethasone are neuroprotective agents. However, to apply new treatments of ICH in clinic needs much more randomized controlled trials, animal and clinical experiments.

\section{Disclosure Statement}

Thanks to the financial funding of famous professor progress of Xiangya, the key built disciplines of the ministry, and the key research and development program of Hunan Science and Technology Agency (soft science research): analysis of clinical factors and gene polymorphism in progressing hemorrhagic stroke. We have no conflict of interest to claim.

\section{References}

1 Flower O, Smith M: The acute management of intracerebral hemorrhage. Curr Opin Crit Care 2011;17:106-114.

2 van Asch CJ, Luitse MJ, Rinkel GJ, van der Tweel I, Algra A, Klijn CJ: Incidence, case fatality, and functional outcome of intracerebral haemorrhage over time, according to age, sex, and ethnic origin: a systematic review and meta-analysis. Lancet Neurol 2010;9:167176.

3 Keep RF, Hua Y, Xi G: Intracerebral haemorrhage: mechanisms of injury and therapeutic targets. Lancet Neurol 2012;11:720-731.

4 Xi G, Keep RF, Hoff JT: Mechanisms of brain injury after intracerebral haemorrhage. Lancet Neurol 2006;5:53-63.

5 Hoff JT, Xi G: Brain edema from intracerebral hemorrhage. Acta Neurochir Suppl 2003;86: 11-15.

6 Bakhshayesh B, Hosseininezhad M, Saadat SN, Ansar MM, Ramezani H, Saadat SM: Iron overload is associated with perihematoma edema growth following intracerebral hemorrhage that may contribute to in-hospital mortality and long-term functional outcome. Curr Neurovasc Res 2014;11:248-253.

7 Wang J, Doré S: Inflammation after intracerebral hemorrhage. J Cereb Blood Flow Metab 2007;27:894-908.

8 Lu L, Barfejani AH, Qin T, Dong Q, Ayata C, Waeber C: Fingolimod exerts neuroprotective effects in a mouse model of intracerebral hemorrhage. Brain Res 2014;1555:89-96.

$9 \mathrm{Fu} \mathrm{Y,} \mathrm{Hao} \mathrm{J,} \mathrm{Zhang} \mathrm{N,} \mathrm{Ren} \mathrm{L,} \mathrm{Sun} \mathrm{N,} \mathrm{Li} \mathrm{YJ,}$ Yan Y, Huang D, Yu C, Shi FD: Fingolimod for the treatment of intracerebral hemorrhage: a 2-arm proof-of-concept study. JAMA Neurol 2014;71:1092-1101.

10 Lee IN, Cheng WC, Chung CY, Lee MH, Lin $\mathrm{MH}$, Kuo $\mathrm{CH}$, Weng HH, Yang JT: Dexamethasone reduces brain cell apoptosis and inhibits inflammatory response in rats with intracerebral hemorrhage. J Neurosci Res 2015;93:178-188.
11 Selim M: Deferoxamine mesylate: a new hope for intracerebral hemorrhage: from bench to clinical trials. Stroke 2009;40(3 suppl):S90S91.

12 Venkatasubramanian C, Mlynash M, FinleyCaulfield A, Eyngorn I, Kalimuthu R, Snider RW, Wijman CA: Natural history of perihematomal edema after intracerebral hemorrhage measured by serial magnetic resonance imaging. Stroke 2011;42:73-80.

13 Wagner KR, Xi G, Hua Y, Kleinholz M, de Courten-Myers GM, Myers RE, Broderick JP, Brott TG: Lobar intracerebral hemorrhage model in pigs: rapid edema development in perihematomal white matter. Stroke 1996;27: 490-497.

14 Ziai WC: Hematology and inflammatory signaling of intracerebral hemorrhage. Stroke 2013;44(6 suppl 1):S74-S78.

15 Chen S, Zeng L, Hu Z: Progressing haemorrhagic stroke: categories, causes, mechanisms and managements. J Neurol 2014;261:20612078.

16 Xi G, Wagner KR, Keep RF, Hua Y, de Courten-Myers GM, Broderick JP, Brott TG, Hoff JT: Role of blood clot formation on early edema development after experimental intracerebral hemorrhage. Stroke 1998;29:25802586.

17 Kuroiwa T, Shibutani M, Tajima T, Hirasawa $\mathrm{H}$, Okeda R: Hydrostatic pressure versus osmotic pressure in the development of vasogenic brain edema induced by cold injury. Adv Neurol 1990;52:11-19.

18 Linfante I, Llinas RH, Caplan LR, Warach S: MRI features of intracerebral hemorrhage within 2 hours from symptom onset. Stroke 1999;30:2263-2267.

19 Butcher KS, Baird T, MacGregor L, Desmond P, Tress B, Davis S: Perihematomal edema in primary intracerebral hemorrhage is plasma derived. Stroke 2004;35:1879-1885.

20 Gebel JM, Brott TG, Sila CA, Tomsick TA, Jauch E, Salisbury S, Khoury J, Miller R, Pan- cioli A, Duldner JE, Topol EJ, Broderick JP: Decreased perihematomal edema in thrombolysis-related intracerebral hemorrhage compared with spontaneous intracerebral hemorrhage. Stroke 2000;31:596-600.

21 Kuroiwa T, Cahn R, Juhler M, Goping G, Campbell G, Klatzo I: Role of extracellular proteins in the dynamics of vasogenic brain edema. Acta Neuropathol 1985;66:3-11.

22 Wagner KR, Dean C, Beiler S, Bryan DW, Packard BA, Smulian AG, Linke MJ, de Courten-Myers GM: Plasma infusions into porcine cerebral white matter induce early edema, oxidative stress, pro-inflammatory cytokine gene expression and DNA fragmentation: implications for white matter injury with increased blood-brain-barrier permeability. Curr Neurovasc Res 2005;2:149-155.

23 Gong C, Hoff JT, Keep RF: Acute inflammatory reaction following experimental intracerebral hemorrhage in rat. Brain Res 2000;871: 57-65.

24 Wang J: Preclinical and clinical research on inflammation after intracerebral hemorrhage. Prog Neurobiol 2010;92:463-477.

25 Mracsko E, Javidi E, Na SY, Kahn A, Liesz A, Veltkamp R: Leukocyte invasion of the brain after experimental intracerebral hemorrhage in mice. Stroke 2014;45:2107-2114.

26 Hammond MD, Ai Y, Sansing LH: Gr1+ macrophages and dendritic cells dominate the inflammatory infiltrate 12 hours after experimental intracerebral hemorrhage. Transl Stroke Res 2012;3:s125-s131.

27 Nguyen HX, O’Barr TJ, Anderson AJ: Polymorphonuclear leukocytes promote neurotoxicity through release of matrix metalloproteinases, reactive oxygen species, and TNFalpha. J Neurochem 2007;102:900-912.

28 Joice SL, Mydeen F, Couraud PO, Weksler BB, Romero IA, Fraser PA, Easton AS: Modulation of blood-brain barrier permeability by neutrophils: in vitro and in vivo studies. Brain Res 2009;1298:13-23. 
29 Zhao X, Sun G, Zhang J, Strong R, Song W, Gonzales N, Grotta JC, Aronowski J: Hematoma resolution as a target for intracerebral hemorrhage treatment: role for peroxisome proliferator-activated receptor gamma in $\mathrm{mi}-$ croglia/macrophages. Ann Neurol 2007;61: 352-362.

30 van Rossum D, Hanisch UK: Microglia. Metab Brain Dis 2004;19:393-411.

31 Lin S, Yin Q, Zhong Q, Lv FL, Zhou Y, Li JQ, Wang JZ, Su BY, Yang QW: Heme activates TLR4-mediated inflammatory injury via MyD88/TRIF signaling pathway in intracerebral hemorrhage. J Neuroinflammation 2012; 9:46.

32 Wang J, Doré S: Heme oxygenase-1 exacerbates early brain injury after intracerebral haemorrhage. Brain 2007;130(pt 6):16431652.

33 Taylor RA, Sansing LH: Microglial responses after ischemic stroke and intracerebral hemorrhage. Clin Dev Immunol 2013;2013: 746068.

34 Teng W, Wang L, Xue W, Guan C: Activation of TLR4-mediated NFkappaB signaling in hemorrhagic brain in rats. Mediators Inflamm 2009;2009:473276.

35 Yang Z, Liu B, Zhong L, Shen H, Lin C, Lin L, Zhang N, Yuan B: Toll-like receptor-4-mediated autophagy contributes to microglial activation and inflammatory injury in mouse models of intracerebral haemorrhage. Neuropathol Appl Neurobiol 2015;41:e95-e106.

36 Sansing LH, Harris TH, Welsh FA, Kasner SE, Hunter CA, Kariko K: Toll-like receptor 4 contributes to poor outcome after intracerebral hemorrhage. Ann Neurol 2011;70:646656.

37 Lee KR, Kawai N, Kim S, Sagher O, Hoff JT: Mechanisms of edema formation after intracerebral hemorrhage: effects of thrombin on cerebral blood flow, blood-brain barrier permeability, and cell survival in a rat model. J Neurosurg 1997;86:272-278.

38 Guan JX, Sun SG, Cao XB, Chen ZB, Tong ET: Effect of thrombin on blood brain barrier permeability and its mechanism. Chin Med J (Engl) 2004;117:1677-1681.

39 Senn R, Elkind MS, Montaner J, Christ-Crain M, Katan M: Potential role of blood biomarkers in the management of nontraumatic intracerebral hemorrhage. Cerebrovasc Dis 2014; 38:395-409.

40 Liu DZ, Ander BP, Xu H, Shen Y, Kaur P, Deng W, Sharp FR: Blood-brain barrier breakdown and repair by Src after thrombininduced injury. Ann Neurol 2010;67:526533.

41 Liu DZ, Sharp FR: The dual role of SRC kinases in intracerebral hemorrhage. Acta Neurochir Suppl 2011;111:77-81.

42 Babu R, Bagley JH, Di C, Friedman AH, Adamson C: Thrombin and hemin as central factors in the mechanisms of intracerebral hemorrhage-induced secondary brain injury and as potential targets for intervention. Neurosurg Focus 2012;32:E8.
43 Ohnishi M, Katsuki H, Fujimoto S, Takagi M, Kume T, Akaike A: Involvement of thrombin and mitogen-activated protein kinase pathways in hemorrhagic brain injury. Exp Neurol 2007;206:43-52.

44 Bhasin RR, Xi G, Hua Y, Keep RF, Hoff JT: Experimental intracerebral hemorrhage: effect of lysed erythrocytes on brain edema and blood-brain barrier permeability. Acta Neurochir Suppl 2002;81:249-251.

45 Shi BZ, Meng XF, Yang JX, Hao XW, Cui T, Lu ZF, Zhang HR, Zhou JC, Liu JF: Effect of erythrocytes on brain water content and haem oxygenase-1 expression in rats with traumatic intracerebral haemorrhage. Acta Neurochir (Wien) 2012;154:1081-1086; discussion 1086

46 Qing WG, Dong YQ, Ping TQ, Lai LG, Fang LD, Min HW, Xia L, Heng PY: Brain edema after intracerebral hemorrhage in rats: the role of iron overload and aquaporin 4 . J Neurosurg 2009;110:462-468.

$47 \mathrm{Xu}$ J, Qiu GP, Huang J, Zhang B, Sun SQ, Gan SW, Lu WT, Wang KJ, Huang SQ, Zhu SJ: Internalization of aquaporin- 4 after collagenase-induced intracerebral hemorrhage. Anat Rec (Hoboken) 2015;298:554-561.

48 Wang YC, Zhou Y, Fang H, Lin S, Wang PF, Xiong RP, Chen J, Xiong XY, Lv FL, Liang QL, Yang QW: Toll-like receptor 2/4 heterodimer mediates inflammatory injury in intracerebral hemorrhage. Ann Neurol 2014;75:876-889.

49 Hertz L, Xu J, Chen Y, Gibbs ME, Du T, et al: Antagonists of the vasopressin V1 receptor and of the $\beta(1)$-adrenoceptor inhibit cytotoxic brain edema in stroke by effects on astrocytes - but the mechanisms differ. Curr Neuropharmacol 2014;12:308-323.

50 Zhao XY, Wu CF, Yang J, Gao Y, Sun FJ, Wang DX, Wang CH, Lin BC: Effect of arginine vasopressin on the cortex edema in the ischemic stroke of Mongolian gerbils. Neuropeptides 2015;51:55-62.

51 Manaenko A, Fathali N, Khatibi NH, Lekic T, Shum KJ, Martin R, Zhang JH, Tang J: Posttreatment with SR49059 improves outcomes following an intracerebral hemorrhagic stroke in mice. Acta Neurochir Suppl 2011; 111:191-196

52 Manaenko A, Fathali N, Khatibi NH, Lekic T, Hasegawa Y, Martin R, Tang J, Zhang JH: Arginine-vasopressin V1a receptor inhibition improves neurologic outcomes following an intracerebral hemorrhagic brain injury. Neurochem Int 2011;58:542-548.

53 Qureshi AI, Ali Z, Suri MF, Shuaib A, Baker G, Todd K, Guterman LR, Hopkins LN: Extracellular glutamate and other amino acids in experimental intracerebral hemorrhage: an in vivo microdialysis study. Crit Care Med 2003, 31:1482-1489.

54 da Silva-Candal A, Vieites-Prado A, Gutiérrez-Fernández M, Rey RI, Argibay B, Mirelman D, Sobrino T, Rodríguez-Frutos B, Castillo J, Campos F: Blood glutamate grabbing does not reduce the hematoma in an intracerebral hemorrhage model but it is a safe exci- totoxic treatment modality. J Cereb Blood Flow Metab 2015;35:1206-1212.

55 Wang LK, Hong Z, Wu GF, Li C: Perihematomal endothelin-1 level is associated with an increase in blood-brain barrier permeability in a rabbit model of intracerebral hematoma. Chin Med J (Engl) 2013;126:3433-3438.

56 Bickford JS, Ali NF, Nick JA, Al-Yahia M, Beachy DE, Doré S, Nick HS, Waters MF: Endothelin-1-mediated vasoconstriction alters cerebral gene expression in iron homeostasis and eicosanoid metabolism. Brain Res 2014; 1588:25-36.

57 Zazulia AR, Diringer MN, Derdeyn CP, Powers WJ: Progression of mass effect after intracerebral hemorrhage. Stroke 1999;30:11671173.

58 Gebel JM Jr, Jauch EC, Brott TG, Khoury J, Sauerbeck L, Salisbury S, Spilker J, Tomsick TA, Duldner J, Broderick JP: Relative edema volume is a predictor of outcome in patients with hyperacute spontaneous intracerebral hemorrhage. Stroke 2002;33:2636-2641.

59 Gupta M, Verma R, Parihar A, Garg RK Singh MK, Malhotra HS: Perihematomal ede$\mathrm{ma}$ as predictor of outcome in spontaneous intracerebral hemorrhage. J Neurosci Rural Pract 2014;5:48-54.

60 Sonni S, Lioutas VA, Selim MH: New avenues for treatment of intracranial hemorrhage. Curr Treat Options Cardiovasc Med 2014;16: 277.

61 Qureshi AI, Palesch YY, Martin R, Novitzke J, Cruz-Flores S, Ehtisham A, Ezzeddine MA, Goldstein JN, Hussein HM, Suri MF, Tariq N: Effect of systolic blood pressure reduction on hematoma expansion, perihematomal ede$\mathrm{ma}$, and 3-month outcome among patients with intracerebral hemorrhage: results from the antihypertensive treatment of acute cerebral hemorrhage study. Arch Neurol 2010;67: 570-576.

62 Qureshi AI, Palesch YY, Martin R, Toyoda K, Yamamoto $\mathrm{H}$, Wang Y, Wang Y, Hsu CY, Yoon BW, Steiner T, Butcher K, Hanley DF, Suarez JI: Interpretation and implementation of intensive blood pressure reduction in acute cerebral hemorrhage trial (INTERACT II). J Vasc Interv Neurol 2014;7:34-40.

63 Qureshi AI, Palesch YY: Antihypertensive treatment of acute cerebral hemorrhage (ATACH) II: design, methods, and rationale. Neurocrit Care 2011;15:559-576.

64 Kobayashi J, Koga M, Tanaka E, Okada Y, Kimura K, Yamagami H, Okuda S, Hasegawa Y, Shiokawa Y, Furui E, Nakagawara J, Kario K, Okata T, Arihiro S, Sato S, Nagatsuka K, Minematsu K, Toyoda K: Continuous antihypertensive therapy throughout the initial 24 hours of intracerebral hemorrhage: the stroke acute management with urgent risk-factor assessment and improvement-intracerebral hemorrhage study. Stroke 2014;45:868-870.

65 Zhou Y, Wang Y, Wang J, Anne Stetler R, Yang QW: Inflammation in intracerebral hemorrhage: from mechanisms to clinical translation. Prog Neurobiol 2014;115:25-44. 
66 Joshi S, Singh-Moon R, Wang M, Bruce JN, Bigio IJ, Mayevsky A: Real-time hemodynamic response and mitochondrial function changes with intracarotid mannitol injection. Brain Res 2014;1549:42-51.

67 Rapoport SI: Osmotic opening of the bloodbrain barrier: principles, mechanism, and therapeutic applications. Cell Mol Neurobiol 2000;20:217-230.

68 Kaufmann AM, Cardoso ER: Aggravation of vasogenic cerebral edema by multiple-dose mannitol. J Neurosurg 1992;77:584-589.

69 Diringer MN, Zazulia AR: Osmotic therapy: fact and fiction. Neurocrit Care 2004;1:219233.

70 Misra UK, Kalita J, Ranjan P, Mandal SK: Mannitol in intracerebral hemorrhage: a randomized controlled study. J Neurol Sci 2005; 234:41-45.

71 Qureshi AI, Mendelow AD, Hanley DF: Intracerebral haemorrhage. Lancet 2009;373. 1632-1644.

72 Qureshi AI, Wilson DA, Traystman RJ: Treatment of elevated intracranial pressure in experimental intracerebral hemorrhage: comparison between mannitol and hypertonic saline. Neurosurgery 1999;44:10551063; discussion 1063-1064

73 Thenuwara K, Todd MM, Brian JE Jr: Effect of mannitol and furosemide on plasma osmolality and brain water. Anesthesiology 2002; 96:416-421.

74 Mayzler O, Leon A, Eilig I, Fuxman Y, Benifla M, Freixo PC, Gurevich B, Agassi R, Artru AA, Shapria Y: The effect of hypertonic (3\%) saline with and without furosemide on plasma osmolality, sodium concentration, and brain water content after closed head trauma in rats. J Neurosurg Anesthesiol 2006;18:2431.

75 Morgenstern LB, Hemphill JC 3rd, Anderson C, Becker K, Broderick JP, Connolly ES Jr, Greenberg SM, Huang JN, MacDonald RL, Messé SR, Mitchell PH, Selim M, Tamargo RJ: Guidelines for the management of spontaneous intracerebral hemorrhage: a guideline for healthcare professionals from the American Heart Association/American Stroke Association. Stroke 2010;41:2108-2129.

76 Sansing LH, Harris TH, Kasner SE, Hunter CA, Kariko K: Neutrophil depletion diminishes monocyte infiltration and improves functional outcome after experimental intracerebral hemorrhage. Acta Neurochir Suppl 2011;111:173-178.

77 Moxon-Emre I, Schlichter LC: Neutrophil depletion reduces blood-brain barrier breakdown, axon injury, and inflammation after intracerebral hemorrhage. J Neuropathol Exp Neurol 2011;70:218-235.

78 Wu J, Yang S, Hua Y, Liu W, Keep RF, Xi G: Minocycline attenuates brain edema, brain atrophy and neurological deficits after intracerebral hemorrhage. Acta Neurochir Suppl 2010;106:147-150.

79 Wasserman JK, Schlichter LC: Minocycline protects the blood-brain barrier and reduces edema following intracerebral hemorrhage in the rat. Exp Neurol 2007;207:227-237.

80 Zhao F, Hua Y, He Y, Keep RF, Xi G: Minocycline-induced attenuation of iron overload and brain injury after experimental intracerebral hemorrhage. Stroke 2011;42:3587-3593.

81 Wang J, Tsirka SE: Tuftsin fragment $1-3$ is beneficial when delivered after the induction of intracerebral hemorrhage. Stroke 2005;36: 613-618.

82 Rolland WB 2nd, Manaenko A, Lekic T, Hasegawa Y, Ostrowski R, Tang J, Zhang JH: FTY720 is neuroprotective and improves functional outcomes after intracerebral hemorrhage in mice. Acta Neurochir Suppl 2011; 111:213-217.

83 Rolland WB, Lekic T, Krafft PR, Hasegawa Y, Altay O, Hartman R, Ostrowski R, Manaenko A, Tang J, Zhang JH: Fingolimod reduces cerebral lymphocyte infiltration in experimental models of rodent intracerebral hemorrhage. Exp Neurol 2013;241:45-55.

84 Yang JT, Lee TH, Lee IN, Chung CY, Kuo CH, Weng HH: Dexamethasone inhibits ICAM-1 and MMP-9 expression and reduces brain edema in intracerebral hemorrhagic rats. Acta Neurochir (Wien) 2011;153:2197-2203.

85 Gong Y, Xi GH, Keep RF, Hoff JT, Hua Y: Complement inhibition attenuates brain edema and neurological deficits induced by thrombin. Acta Neurochir Suppl 2005;95: 389-392.

86 Gu Y, Hua Y, Keep RF, Morgenstern LB, Xi G: Deferoxamine reduces intracerebral hematoma-induced iron accumulation and neuronal death in piglets. Stroke 2009;40:2241-2243.

87 Xie Q, Gu Y, Hua Y, Liu W, Keep RF, Xi G: Deferoxamine attenuates white matter injury in a piglet intracerebral hemorrhage model. Stroke 2014;45:290-292.

88 Okauchi M, Hua Y, Keep RF, Morgenstern LB, Xi G: Effects of deferoxamine on intracerebral hemorrhage-induced brain injury in aged rats. Stroke 2009;40:1858-1863.

89 Hatakeyama T, Okauchi M, Hua Y, Keep RF, Xi G: Deferoxamine reduces neuronal death and hematoma lysis after intracerebral hemorrhage in aged rats. Transl Stroke Res 2013; 4:546-553.

90 Wan S, Hua Y, Keep RF, Hoff JT, Xi G: Deferoxamine reduces CSF free iron levels following intracerebral hemorrhage. Acta Neurochir Suppl 2006;96:199-202.

91 Wang J, Zhuang H, Doré S: Heme oxygenase 2 is neuroprotective against intracerebral hemorrhage. Neurobiol Dis 2006;22:473-476.

92 Wang YC, Wang PF, Fang H, Chen J, Xiong XY, Yang QW: Toll-like receptor 4 antagonist attenuates intracerebral hemorrhage-induced brain injury. Stroke 2013;44:25452552.

93 Tapia-Pérez JH, Rupa R, Zilke R, Gehring S, Voellger B, Schneider T: Continued statin therapy could improve the outcome after spontaneous intracerebral hemorrhage. Neurosurg Rev 2013;36:279-287; discussion 287.
94 Loftspring MC, Johnson HL, Johnson AJ, Clark JF: Depletion of GR-1-positive cells is associated with reduced neutrophil inflammation and astrocyte reactivity after experimental intracerebral hemorrhage. Transl Stroke Res 2012;3(suppl 1):147-154.

95 Wang J, Fields J, Zhao C, Langer J, Thimmulappa RK, Kensler TW, Yamamoto M, Biswal S, Doré S: Role of Nrf2 in protection against intracerebral hemorrhage injury in mice. Free Radic Biol Med 2007;43:408-414.

$96 \mathrm{Lu} \mathrm{H}$, Shen J, Song X, Ge J, Cai R, Dai A, Jiang Z: Protective effect of pyrroloquinoline quinone (PQQ) in rat model of intracerebral hemorrhage. Cell Mol Neurobiol 2015;35: 921-930.

97 Chu H, Tang Y, Dong Q: Protection of granulocyte-colony stimulating factor to hemorrhagic brain injuries and its involved mechanisms: effects of vascular endothelial growth factor and aquaporin-4. Neuroscience 2014; 260:59-72.

98 Chu H, Ding H, Tang Y, Dong Q: Erythropoietin protects against hemorrhagic bloodbrain barrier disruption through the effects of aquaporin-4. Lab Invest 2014;94:10421053.

99 Okuda M, Suzuki R, Moriya M, Fujimoto $M$, Chang CW, Fujimoto T: The effect of hematoma removal for reducing the development of brain edema in cases of putaminal hemorrhage. Acta Neurochir Suppl 2006; 96:74-77.

100 Kaya RA, Türkmenoğlu O, Ziyal IM, Dalkiliç T, Sahin Y, Aydin Y: The effects on prognosis of surgical treatment of hypertensive putaminal hematomas through transsylvian transinsular approach. Surg Neurol 2003;59: 176-183; discussion 183.

101 Zuo Y, Cheng G, Gao DK, Zhang X, Zhen HN, Zhang W, Xiao SC: Gross-total hematoma removal of hypertensive basal ganglia hemorrhages: a long-term follow-up. J Neurol Sci 2009;287:100-104.

102 Mendelow AD, Gregson BA, Fernandes HM, Murray GD, Teasdale GM, Hope DT, Karimi A, Shaw MD, Barer DH: Early surgery versus initial conservative treatment in patients with spontaneous supratentorial intracerebral haematomas in the international surgical trial in intracerebral haemorrhage (STICH): a randomised trial. Lancet 2005; 365:387-397.

103 Gregson BA, Broderick JP, Auer LM, Batjer $\mathrm{H}$, Chen XC, Juvela S, Morgenstern LB, Pantazis GC, Teernstra OP, Wang WZ, Zuccarello $\mathrm{M}$, Mendelow AD: Individual patient data subgroup meta-analysis of surgery for spontaneous supratentorial intracerebral hemorrhage. Stroke 2012;43:1496-1504.

104 Mendelow AD, Gregson BA, Rowan EN, Murray GD, Gholkar A, Mitchell PM: Early surgery versus initial conservative treatment in patients with spontaneous supratentorial lobar intracerebral haematomas (STICH II): a randomised trial. Lancet 2013;382:397408. 
105 Zhou X, Chen J, Li Q, Ren G, Yao G, Liu M, Dong Q, Guo J, Li L, Guo J, Xie P: Minimally invasive surgery for spontaneous supratentorial intracerebral hemorrhage: a metaanalysis of randomized controlled trials. Stroke 2012;43:2923-2930.

106 Kirollos RW, Tyagi AK, Ross SA, van Hille PT, Marks PV: Management of spontaneous cerebellar hematomas: a prospective treatment protocol. Neurosurgery 2001;49: 1378-1386; discussion 1386-1387.

107 Witsch J, Neugebauer H, Zweckberger K, Jüttler E: Primary cerebellar haemorrhage: complications, treatment and outcome. Clin Neurol Neurosurg 2013;115:863-869.

108 Papacocea A, Papacocea T, Dănăilă L, Ion D, Bădărău A, Papacocea R: [Primary intracerebellar hematomas: surgical indications, prognosis]. Chirurgia (Bucur) 2010;105: 805-807.

109 Barnes B, Hanley DF, Carhuapoma JR: Minimally invasive surgery for intracerebral haem- orrhage. Curr Opin Crit Care 2014;20:148152.

110 Dey M, Stadnik A, Awad IA: Thrombolytic evacuation of intracerebral and intraventricular hemorrhage. Curr Cardiol Rep 2012;14: 754-760.

111 Wu G, Li C, Wang L, Mao Y, Hong Z: Minimally invasive procedures for evacuation of intracerebral hemorrhage reduces perihematomal glutamate content, bloodbrain barrier permeability and brain edema in rabbits. Neurocrit Care 2011;14: 118-126.

112 Wang L, Wang F, Wu G, Shi J: Early-stage minimally invasive procedures decrease perihematomal endothelin-1 levels and improve neurological functioning in a rabbit model of intracerebral hemorrhage. Neurol Res 2015;37:320-327.

113 Lian LF, Xu F, Tang ZP, Xue Z, Liang QM, Hu Q, Zhu WH, Kang HC, Liu XY, Wang FR, Zhu SQ: Intraclot recombinant tissue- type plasminogen activator reduces perihematomal edema and mortality in patients with spontaneous intracerebral hemorrhage. J Huazhong Univ Sci Technolog Med Sci 2014;34:165-171.

114 Krylov VV, Burov SA, Dash'ian VG, Galankina IE: [Local fibrinolysis in surgical treatment of non-traumatic intracranial hemorrhages]. Vestn Ross Akad Med Nauk 2013;7:24-31.

115 Li Y, Zhang H, Wang X, She L, Yan Z, Zhang N, Du R, Yan K, Xu E, Pang L: Neuroendoscopic surgery versus external ventricular drainage alone or with intraventricular fibrinolysis for intraventricular hemorrhage secondary to spontaneous supratentorial hemorrhage: a systematic review and meta-analysis. PLoS One 2013;8:e80599.

116 Liu J, Huang Y, Wang A: Diagnosis and treatment of intracerebral tension hematoma following cerebral hemorrhage. J Int Neurol Neurosurg 2009;5:400-402. 